\title{
An observational study of protective equipment use among in-line skaters
} Lynne Warda, Sande Harlos, Terry P Klassen, Michael E K Moffatt, Norma Buchan,
Virginia L Koop

\begin{abstract}
Objectives-To describe the patterns of protective equipment use by in-line skaters in Winnipeg, Manitoba and nearby rural communities.

Methods-In-line skaters were observed for three months in 1996 at 190 urban and 30 rural sites selected using a formal sampling scheme. Age, gender, protective equipment use, skating companions, correct helmet use, and use of headphones were recorded.

Results-Altogether 123 in-line skaters were observed at 61 sites, including one rural site. No skaters were observed at the remaining sites. There were 37 adults and 86 children; $56 \%$ were male. Helmet use was $12.2 \%(95 \%$ confidence interval $(\mathrm{CI})=$ $6.4 \%$ to $18.0 \%$ ), wrist guard use was $16.3 \%$ (95\% CI $=9.7 \%$ to $22.8 \%$ ), knee pad use was $9.8 \%(95 \% \mathrm{CI}=5.2 \%$ to $16.4 \%)$, and elbow pad use was $7.3 \%(95 \% \mathrm{CI}=3.4 \%$ to $13.4 \%)$. Children were more likely to wear a helmet than teens 12-19 years of age (relative risk $(\mathrm{RR})=30,95 \% \mathrm{CI}=4.01$ to 225). Adults were more likely to wear wrist guards than children $(R R=4.32,95 \% \mathrm{CI}=$ 1.87 to 9.94$)$. No gender differences were found. Incorrect helmet use was documented in four skaters; three skaters were wearing headphones.

Conclusions-Low rates of protective equipment use were documented in our region, significantly lower than those reported in the literature. Barriers to equipment use are not known, and should be examined by further study. In-line skating safety programs should be developed, promoted, and evaluated. Teens should be targeted for future preventive efforts.

(Injury Prevention 1998;4:198-202)
\end{abstract}

Keywords: in-line skating; protective equipment; helmet use

In-line skating is a popular recreational and competitive sport with a growing number of enthusiasts worldwide. In-line skates differ from rollerskates in the number and alignment of wheels; in-line skates have 3-5 low friction polyurethane wheels arranged in a single row, attached by a frame to the sole of the boot, whereas rollerskates typically have two pairs of wheels. In-line skates were designed for enhanced maneuverability and offer skaters greater speed and agility. "Rollerblading", as the sport is commonly known, was reportedly the fastest growing recreational sport in the US in the early to mid-1990s. In 1993 there were an estimated 12.6 million in-line skaters in the US, of whom approximately $75 \%$ were under the age of 25 years. ${ }^{1}$

As in-line skating grew in popularity, injuries were reported at an alarming rate. ${ }^{2-4}$ Over a two year period from 1992 to 1993 there were an estimated 66465 in-line skating injuries in the US, with an estimated $60 \%$ of these injuries occurring in skaters less than 20 years of age. The mean age of the injured skaters was 11.8 years. Fractures were found in $45 \%$ of injuries to young skaters, and $2.5 \%$ of injured skaters required admission to hospital. ${ }^{5}$ The use of protective equipment by in-line skaters is known to be associated with lower risk of injury. ${ }^{6}$ Rates of use of protective equipment are highly variable, however, in the few reported observational studies. ${ }^{7-9}$ There are only two studies with adequate observation methodology, ${ }^{89}$ and only one of these used a formal sampling scheme including stratified random sampling. ${ }^{8}$

The purpose of this study is to document the use of protective equipment by in-line skaters in Winnipeg, Manitoba and nearby rural communities, and to identify factors predicting non-use, in order to develop preventive measures.

\section{Methods}

SUBJECT AND SITE SELECTION

Subjects were all in-line skaters observed between 28 May and 20 August 1996 in 190 urban sites in the city of Winnipeg and in 30 nearby rural communities. In-line skaters of all ages were included. Gender and age were categorized by observation without stopping the skaters for verification. This study was conducted concurrently with a bicycle helmet observation study.

Observations were made at five location types: parks, schools, residential streets, major intersections, and cycling paths. In Winnipeg, an equal number of schools and parks (40) were randomly selected from sampling frames of all elementary schools and parks. Observations were made at cycling paths in parks where paths were present (2). For major intersections and residential street locations, a city map divided into 190 neighborhoods was used. Neighborhoods without a school or park already assigned (110) were alternately assigned to residential street or major intersection. The city map was divided into six zones, and the observation sites were plotted on the map to ensure that equal numbers of each of the five location types were assigned 
Table 1 Use of protective equipment by in-line skaters; values are number (\%)

\begin{tabular}{|c|c|c|c|c|c|c|c|c|}
\hline & \multicolumn{2}{|l|}{ Gender } & \multicolumn{4}{|l|}{ Age (years) } & \multirow[b]{2}{*}{$\begin{array}{l}\text { Total } \\
(n=123)\end{array}$} & \multirow[b]{2}{*}{$\begin{array}{l}\text { Adults } \\
(n=37)\end{array}$} \\
\hline & $\begin{array}{l}\text { Male } \\
(n=69)\end{array}$ & $\begin{array}{l}\text { Female } \\
(n=54)\end{array}$ & $<8(n=14)$ & $\begin{array}{l}8-11 \\
(n=12)\end{array}$ & $\begin{array}{l}12-15 \\
(n=31)\end{array}$ & $\begin{array}{l}16-19 \\
(n=29)\end{array}$ & & \\
\hline Helmet & $7(10.1)$ & $8(14.8)$ & $7(50.0)$ & $1(8.3)$ & 0 & $1(3.4)$ & $6(16.2)$ & $15(12.2)$ \\
\hline Wrist guards & $11(15.9)$ & $9(16.7)$ & $3(21.4)$ & 0 & $1(3.2)$ & $3(10.3)$ & $13(35.1)$ & $20(16.3)$ \\
\hline Elbow pads & $3(4.3)$ & $6(11.1)$ & $3(21.4)$ & 0 & $1(3.2)$ & $1(3.4)$ & $4(10.8)$ & $9(7.3)$ \\
\hline Knee pads & $5(7.2)$ & $7(13.0)$ & $2(14.3)$ & 0 & $2(6.5)$ & $2(6.9)$ & $6(16.2)$ & $12(9.8)$ \\
\hline Brake & $59(85.5)$ & $54(100.0)$ & $14(100.0)$ & $12(100.0)$ & $26(83.9)$ & $24(82.8)$ & $37(100.0)$ & $113(91.9)$ \\
\hline No gear & $9(13.0)$ & 0 & 0 & 0 & $4(12.9)$ & $5(17.2)$ & 0 & $9(7.3)$ \\
\hline
\end{tabular}

to each zone. Equal assignment of cycling paths was not possible due to small numbers (2).

Rural site locations were determined by drawing a $60 \mathrm{~km}$ radius from the centre of Winnipeg on a map and dividing the area into quadrants. The largest communities in each quadrant were selected, and smaller communities were chosen at random. Two centres were assigned two observation sites due to their larger populations. In all other rural communities, either a school, park, residential street, or major intersection, was chosen. In many communities the only park was located at a school. One rural cycling path was observed.

DATA COLLECTION

A single, trained observer conducted all observations. Training was done by an experienced research nurse from Injuries ManitobaPrevention of Adolescent and Childhood Trauma (IM-PACT), the injury prevention centre at the Children's Hospital. A minimum of 20 minutes and a maximum of 60 minutes was spent at each site. One third of observations were done on weekends and one sixth were scheduled for the early evening. To limit the possibility of duplicating observations, the observer chose different areas of the city on consecutive days. Observations were made in all weather conditions. Site location, date, and site characteristics were recorded. Observation of cyclists for helmet use was done simultaneously.

For each in-line skater, information was collected on age, gender, use of a helmet, wrist guards, elbow pads, knee pads, and brakes, as well as skating companions (skating with adults, children, or both). Incorrect helmet use and the use of headphones were recorded. Correct helmet use was ascertained by visually assessing obvious fit, positioning on the head, and appropriate strap use. The observer was trained to assess correct fit by a Manitoba Cycling Association instructor.

Field data were entered into a database created in Microsoft Access. The prevalence of protective equipment use with $95 \%$ confidence intervals (CIs) was determined overall and for subgroups of interest. Subgroups were described by the variables age, gender, rural or urban residence, location type, skating companions, and income (urban only). The latter was done by ascertaining the neighborhood household median income for each observation site using a City of Winnipeg map categorizing median income into four strata. Relative risk
(RR) with 95\% CIs were calculated for each proportion using Confidence Interval Analysis Version 1.1, to examine subgroup differences. Bonferroni correction for multiple comparisons was not performed, as data were considered hypothesis generating rather than hypothesis testing.

\section{Results}

Observations were conducted at 220 sites in Manitoba; 190 in the City of Winnipeg and 30 in nearby rural communities. In-line skaters were observed at 61 sites, including one rural site. There were no skaters observed at the remaining sites. A total of 123 skaters were observed, including 37 adults and 86 children. The age distribution was as follows: children less than 8 years $11.4 \%$, children $8-11$ years $9.8 \%, 12-15$ years $25.2 \%, 16-19$ years $23.6 \%$, adults $30 \%$; 69 were male and 54 were female.

Between nine and 19 skaters were observed at each of three sites; fewer than five skaters were observed at each of the remaining sites. The three sites with the largest numbers of skaters included one school and two parks, where observations were made on sunny weekdays, at varying times of day, in May, June, and July. The distribution of skaters by location type was as follows: park $38 \%$, school $24 \%$, major intersection $21 \%$, residential street $12 \%$, and cycling path $4 \%$. Only one skater was observed at a rural location.

PROTECTIVE EQUIPMENT USE

Protective equipment use by age and gender is summarized in table 1 . Females were more likely than males to wear all types of equipment. The highest rates of use were seen in children less than 8 years of age and in adults, and the lowest rates in teens. Most skaters wore at least one piece of protective equipment. Only nine of 123 skaters wore no gear, and these were all males between the ages of 12 and 19 years. There were 10 in-line skaters wearing skates without brakes and three were wearing headphones.

The prevalence of helmet use was $12.2 \%$ $(95 \% \mathrm{CI}=6.4 \%$ to $18.0 \%)$. The rate of helmet use in males was lower but not significantly different to that in females. The highest rate of helmet use was in children less than 8 years of age $(50.0 \%)$ and in adults $(16.2 \%)$, while the lowest rate was in teens aged 12-19 years $(1.7 \%)$. Children less than 8 years of age were significantly more likely to wear a helmet than teens aged $12-19$ years $(\mathrm{RR}=30.0,95 \% \mathrm{CI}=$ 
4.0 to 225.0 ). Helmet use was most common in parks and on residential streets (each $20 \%$ ) and least common on cycling paths (0). Four skaters were observed to wear helmets incorrectly. In each such case, the skater was wearing the helmet too far back.

The prevalence of wrist guard use was $16.3 \%$ (95\% CI $=9.7 \%$ to $22.8 \%$ ), similar among males and females. The highest rate of wrist guard use was in children less than 8 years of age $(21.4 \%)$ and in adults $(35.1 \%)$. Adults were more likely to wear wrist guards than children and adolescents less than 19 years of age $(\mathrm{RR}=4.3,95 \% \mathrm{CI}=1.9$ to 9.9$)$. Wrist guard use was most common in parks, on residential streets, and at major intersections (each $20 \%$ ), and least common on cycling paths $(0)$.

Knee pads were worn by 12 skaters $(9.8 \%$, $95 \% \mathrm{CI}=5.2 \%$ to $16.4 \%)$, more often by females $(13.0 \%, 95 \% \mathrm{CI}=5.4 \%$ to $24.9 \%)$ than males $(7.2 \%, 95 \% \mathrm{CI}=2.4 \%$ to $16.1 \%)$. The highest rates of use were observed in children less than 8 years of age $(14.3 \%)$ and in adults $(16.2 \%)$. Knee pad use was most common on residential streets $(27 \%)$ and least common on cycling paths (0). Nine skaters wore elbow pads $(7.3 \%, 95 \%$ CI $=3.4 \%$ to $13.4 \%$ ), with no gender differences. The highest rates of use were observed among children less than 8 years of age $(21.4 \%)$. Elbow pad use was most common on residential streets $(13 \%)$ and least common on cycling paths $(0)$.

Due to small cell numbers, subgroup analyses for income, skating companions, and ruralurban skaters were not performed.

\section{Discussion}

The International In-line Skating Association recommends the use of helmet, wrist guards, and knee and elbow pads for all skaters. ${ }^{1}$ Although adult skaters often wear protective equipment, teens and children have been reported to wear appropriate equipment less often. ${ }^{9}$ In an analysis of childhood in-line skating injuries in the Canadian Hospitals Injury Reporting and Prevention Program database (1990-92), 88\% of injured skaters reported not wearing any protective equipment. ${ }^{10}$ In one series of in-line skating fractures in children only two of 61 patients were wearing any form of protective equipment. ${ }^{11}$

The wrist is the most common site of injury among in-line skaters, accounting for up to $37 \%$ of injuries. ${ }^{1}$ Wrist fractures are the most common fracture, found in $25 \%$ of injured skaters. ${ }^{67}$ Skaters not wearing wrist guards have a 10 -fold increased risk for wrist injury. ${ }^{6}$ The risk of wrist injury is well known even by novice skaters, and wrist guards are the most commonly worn type of protective equipment. Wrist guard use in our sample $(16.3 \%)$ was much lower than the reported rates of $60-65 \%$ in other observational studies ${ }^{7-9}$ and $33-44 \%$ in several reports of injured skaters. ${ }^{6712}$

Elbow injuries account for approximately $10 \%$ of in-line skating injuries ${ }^{167}$ Skaters not wearing elbow pads have a 9.5-fold increased risk of injury. ${ }^{6}$ Elbow pad use in our sample $(7.3 \%)$ was lower than the reported rates of $15-30 \%$ in two other observational studies ${ }^{8} 9$ (but similar to the low rate of 3\% observed by Adams et $a l^{7}$ ) and 19-32\% among injured skaters. ${ }^{6712}$

Knee injuries account for $5-6 \%$ of in-line skating injuries. ${ }^{16}$ However, knee pads have not been shown to be effective in reducing the risk of knee injuries. We observed knee pad use in less than $10 \%$ of our sample, which is significantly lower than the reported rates of $30-40 \%$ observed in other observational studies $^{89}$ and to the $23-45 \%$ reported in other series of injured skaters. ${ }^{6712}$ Our finding is nevertheless similar to the rate of $13 \%$ observed by Adams et al. ${ }^{7}$

Head injuries occur in approximately $5 \%$ of injured in-line skaters. ${ }^{1}$ Although the effectiveness of helmets in reducing the risk of head injury among in-line skaters is unknown, significant head injuries may occur while in-line skating, as a result of the potential for high speed skating and collisions with motor vehicles. Helmet use is recommended by in-line skating associations and by many experts, but helmets are the least commonly worn piece of protective equipment. Helmet use in our sample, $12.2 \%$, is similar to that reported in the literature in observational studies $(1-9 \%)^{7-9}$ as well as in the series of injured skaters $(2-43 \%){ }^{6}{ }^{710} 12$

Factors associated with the use of protective equipment among in-line skaters include age, gender, income, and skill level. Our sample was of insufficient size to analyze factors such as income or rural residence, and there is only one study in the literature with adequate sample size and design to complete such an analysis. ${ }^{9}$ In summary, teens are the least likely and older skaters the most likely groups to wear at least one piece of protective equipment. Young children are more likely to wear knee pads and helmets, but less likely to wear wrist guards. Females are significantly more likely to wear wrist guards as well as knee or elbow pads than males. Novice skaters are more likely to wear equipment than advanced skaters. ${ }^{9}$

Protective equipment use in our sample varied considerably by location type, with parks and residential streets demonstrating the highest rates of use. Adults and children under 8 years of age were over-represented at these two location types.

The major limitations of our study are its small sample size and small number of observations at certain sites, which precluded further subgroup analyses. Due to our rigorous sampling methods, however, our sample is thought to be representative of the local in-line skating population. Previous studies have used biased sampling methods, including nonrandom site selection or observation of consecutive skaters at a single site. ${ }^{7-9}$

The demographics of our sample are significantly different from other reported series, with a much younger population observed in our study. Age is a significant predictor of protective equipment use, with adults the most likely and teens the least likely to 
wear protective equipment. ${ }^{9}$ Therefore our low rates of use in part reflect the age distribution of our sample.

Skaters in our sample demonstrated significantly lower rates of protective equipment use than those in other observational studies. One such study examined skaters in an affluent community, which may have influenced the use of protective equipment. ${ }^{8}$ Of note, the total rate of helmet use in the concurrent bicycle helmet study was $21 \%$, which is significantly lower than in many other urban areas. There is currently no legislation in Manitoba requiring helmet use by cyclists. Residents of Manitoba appear to be slow or reluctant to accept and use protective equipment, for both cycling and in-line skating.

\section{Implications for prevention}

Several in-line skating safety campaigns have been initiated, but unfortunately none have been evaluated. The International In-line Skating Association developed a "Gear Up" campaign, which promotes the use of protective equipment and encourages skaters to take lessons to improve skills. Rollerblade sponsored an "Asphalt Bites" program, featuring television commercials, giveaways such as T-shirts and stickers, an in-line skating instruction information hotline and school programs. ${ }^{13}$ The American Academy of Orthopaedic Surgeons organized a "Play it Safe" campaign to promote in-line skating safety. ${ }^{14}$ Although the impact of these programs is not known, experience with bicycle helmet campaigns suggests that well designed multilevel efforts are most effective. ${ }^{1516}$

Barriers related to protective equipment use by in-line skaters have not been studied, but may be similar to barriers preventing cyclists from wearing helmets: primarily peer pressure, but also cost, discomfort, and inconvenience. ${ }^{17-22}$ In-line skate and protective equipment manufacturers may have the most powerful effect on equipment use through their manipulation of the image of in-line skaters in the media. Rollerblade's web site, www.roller blade.com, uses cutting edge graphics showing fully geared skaters of all ages. Their "getting started" page links new skaters to the International In-line Skating Association site for information regarding lessons, and also recommends using safety gear. Purchasing a complete set of good protective equipment approximately doubles the cost of a pair of in-line skates. Coupons and other financial incentives, such as packaging skates with equipment at reduced prices, could encourage sales. Manufacturers have responded to skaters' complaints of hot and uncomfortable equipment by introducing more lightweight, cool, and more comfortable lines. Unfortunately, these upgraded lines are more expensive than standard equipment.

The International In-line Skating Association promotes skater training as an essential component of in-line skating safety. Their instructor certification program trains instructors at three levels of expertise, and the associ- ation maintains an international database of instructors for US, Canada, and 15 other countries (www.iisa.org/index.html). Although skater training programs have not been implemented in many communities, skater training courses could be introduced locally in summer camps, community centre programs and schools, either as an after school program or in physical education classes.

Bylaws restricting in-line skating exist in some communities, although there are no regulations regarding the use of safety equipment. Schools could influence young skaters by enforcing rules regarding the use of protective equipment on school property; public parks could introduce similar guidelines.

In summary, in-line skating injury prevention is a relatively new area with a number of questions deserving further research: What are the barriers to wearing protective equipment, and how can they be overcome? Are existing in-line safety programs effective? If not, can existing bicycle campaign "packages" be modified for in-line skating?

On a final note, should sports injury prevention programs focus on safety principles, such as road skills, sports-specific training, and use of protective equipment, rather than specific sports? Multisport campaigns targeting a group of popular activities, for example, sports requiring protective equipment and road skills, such as cycling, in-line skating, and skateboarding could be more cost effective alternatives to single sport campaigns. However, the effectiveness of these generic campaigns requires evaluation. Again, further research is required to develop and refine these potential preventive measures.

This project was funded in part by a research fellowship (LW) awarded by the Children's Hospital Research Foundation of Winnipeg, Manitoba, and by direct support from IM-PACT. Appreciation is expressed to Dr M Tenenbein for review of the manuscript.

1 Schieber RA, Branche-Dorsey CM. In-line skating injuries: epidemiology and recommendations for prevention. Sports Med 1995; 19:427-32.

2 Banas M, Dalldorf P, Marquardt J. Skateboard and in-line skating fractures: a report of one summer's experience. $\mathcal{F}$ Orthop Trauma 1992;6:301-5.

3 Calle S, Eaton R. Wheels in-line roller skating injuries. $\mathcal{f}$ Trauma 1993;6:946-51.

4 Calle S. In-line skating injuries, 1987 through 1992. Am f Public Health 1994;84:675.

5 Powell EC, Tanz RR. In-line skate and rollerskate injuries in childhood. Pediatr Emerg Care 1996;12:259-62.

6 Schieber RA, Branche-Dorsey CM, Ryan GW, et al. Risk factors for injuries from in-line skating and the effectiveness of safety gear. N Engl f Med 1996;335:1630-5.

7 Adams SL, Wyte CD, Paradise MS, et al. A prospective Adams SL, Wyte CD, Paradise MS, et al. A prospective
study of in-line skating: observational series and survey of study of in-line skating: observational series and survey of training. Acad Emerg Med 1996;3:304-11.

8 Jacques LB, Grzesiak E. Personal protective equipment use by in-line roller skaters. F Fam Pract 1994;38:486-8.

9 Young CC, Mark DH. In-line skating: an observational study of protective equipment used by skaters. Arch Fam Med 1995;4:19-23.

10 Ellis JA, Kierulf JC, Klassen TP. Injuries associated with in-line skating from the Canadian Hospitals Injury Reporting and Prevention Program database. Can f Public Health 1995;86:133-6.

11 Mitts KG, Hennrikus WL. In-line skating fractures in children. F Pediatr Orthop 1996;16:640-3.

12 Orenstein JB. Injuries and small-wheel skates. Ann Emerg Med 1996;27:204-9.

13 Consumer Product Safety Commission. CPSC chairman awards safety commendations to Rollerblade and International awards safety commendations to Rollerblade and International In-line Skating A

14 Hensinger RN. In-line skating: play it safe. Am Fam Phys 1996;53:24-30. 
15 Munro J, Coleman P, Nicholl J, et al. Can we prevent accidental injury to adolescents? A systematic review of the evidence. Inj Prev 1995;1:249-55.

16 Centers for Disease Control and Prevention. Injury-control recommendations: bicycle helmets. MMWR Morb Mortal Wkly Rep 1995;44(RR-1):1-16.

17 Otis J, Lesage D, Godin G, et al. Predicting and reinforcing children's intentions to wear protective helmets while bicycling. Public Health Rep 1992;107:283-9.

18 Howland J, Sargent J, Weitzman M, et al. Barriers to bicycle helmet use among children. Am $\mathcal{f}$ Dis Child 1989;143: $741-4$
19 Pendergrast RA, Ashworth CS, DuRant RH, et al. Correlates of children's bicycle helmet use and short-term 1992;90: $354-8$.

20 DiGuiseppi CG, Rivara FP, Koepsell TD. Attitudes toward bicycle helmet ownership and use by school-age children. Am f Dis Child 1990;144:83-6.

21 Finch CF. Teenagers' attitudes towards bicycle helmets three years after the introduction of mandatory wearing. Inj Prev 1996;2:126-30

22 Joshi MS, Beckett K, MacFarlane A. Cycle helmet wearing in teenagers-do health beliefs influence behaviour? Arch Dis Child 1994;71:536-9.

\section{Editorial Board Member: brief biography}

\section{FLAURA KOPLIN WINSTON, MD, PHD, FAAP}

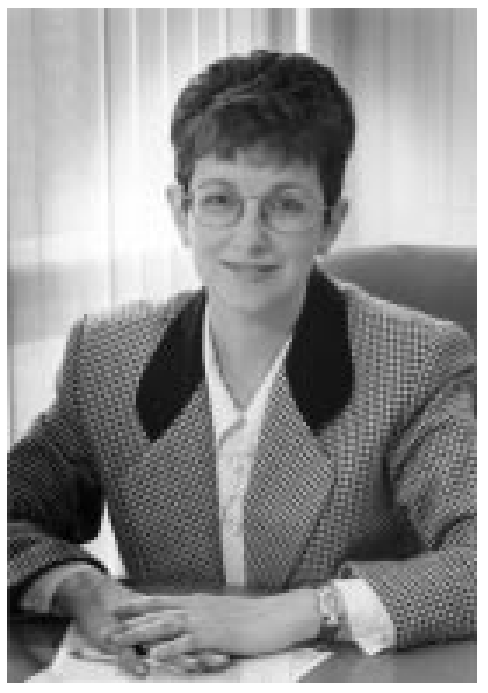

Flaura Winston is a primary care pediatrician in the Division of General Pediatrics at the Children's Hospital of Philadelphia. Dr Winston treats outpatients at the Children's Hospital of Philadelphia's Primary Care Center at 39th Street in West Philadelphia. Dr Winston is also a biomechanical engineer and clinical researcher working on an emergency department based Injury Circumstance Evaluation Study funded by the Emergency Medical Services for Children Program of the Maternal and Child Health Bureau, Health Resources and Services Administration. In addition, she is an Assistant Professor in Pediatrics at the University of Pennsylvania School of Medicine and an Adjunct Assistant Professor in Health Policy and Management at the Johns Hopkins University School of Hygiene and Public Health.

Dr Winston is the principal investigator for Partners for Child Passenger Safety, a research collaboration of the Children's Hospital of Philadelphia, the University of Pennsylvania, and the State Farm Insurance Companies. As the principal investigator, Dr Winston oversees all aspects of the study, sets the direction and timeline of the study, and works with the co-investigator on the interpretation of results. Dr Winston also serves as the primary liaison with the State Farm Insurance Companies, the scientific community, the University of Pennsylvania, the federal government, and industry.

Dr Winston completed her undergraduate and graduate work in bioengineering and pediatrics at the University of Pennsylvania. Dr Winston is currently a Fellow of the American Academy of Pediatrics and a member of the Graduate Group, in the Department of Bioengineering, School of Engineering and Applied Sciences, at the University of Pennsylvania. She completed a postdoctoral fellowship in the Department of Bioengineering, School of Engineering and Applied Sciences, at the University of Pennsylvania and her medical internship and residency in Pediatrics at the Children's Hospital of Philadelphia. Dr Winston was also the First Snively Foundation Injury Prevention Fellow at the Johns Hopkins School of Hygiene and Public Health. She is a member of the American Academy of Pediatrics' Injury and Poison Prevention Section, Physicians for Social Responsibility, the American Public Health Association's Injury Control and Emergency Health Services Section, the Association for the Advancement of Automotive Medicine, the American Society of Mechanical Engineers' Bioengineering Division, and the International Society for Child and Adolescent Injury Prevention.

Married to Ira Winston, Dr Winston has two sons, 8 year old Zachary and 3 year old Andrew and resides in Narberth, Pennsylvania. 